\title{
Hyposensitivity to Gamma-Aminobutyric Acid in the Ventral Tegmental Area During Alcohol Withdrawal: Reversal by Histone Deacetylase Inhibitors
}

\author{
Devinder S Arora', Sudarat Nimitvilai', Tara L Teppen ${ }^{2,3}$, Maureen A McElvain', Amul J Sakharkar ${ }^{2,3}$, \\ Chang You', Subhash C Pandey ${ }^{2,3}$ and Mark S Brodie*, I \\ 'Department of Physiology and Biophysics, University of Illinois, Chicago, IL, USA; 'Department of Psychiatry, University of Illinois, Chicago, IL, USA; \\ ${ }^{3}$ Jesse Brown VA Medical Center, University of Illinois, Chicago, IL, USA
}

\begin{abstract}
Putative dopaminergic (pDAergic) ventral tegmental area (VTA) neurons have an important role in alcohol addiction. Acute ethanol increases the activity of pDAergic neurons, and withdrawal from repeated ethanol administration produces a decreased sensitivity of pDAergic VTA neurons to GABA. Recent studies show that behavioral changes induced by chronic alcohol are reversed by inhibitors of histone deacetylases (HDACs). Whether HDAC-induced histone modifications regulate changes in GABA sensitivity of VTA pDAergic neurons during withdrawal is unknown. Here, we investigated modulation of withdrawal-induced changes in GABA sensitivity of pDAergic VTA neurons by HDAC inhibitors (HDACi), and also measured the levels of HDAC2, histone (H3-K9) acetylation, and GABA-A $\alpha$ I receptor (GABA $(A-\alpha \mid) R$ ) subunit in VTA during ethanol withdrawal. Mice were injected intraperitoneally (ip) with either ethanol $(3.5 \mathrm{~g} / \mathrm{kg})$ or saline twice daily for 3 weeks. In recordings from pDAergic VTA neurons in brain slices from ethanol-withdrawn mice, sensitivity to GABA (50-500 $\mu$ M) was reduced. In brain slices from ethanol-withdrawn mice incubated with the HDACi SAHA (vorinostat) or trichostatin A (TSA) for $2 \mathrm{~h}$, the hyposensitivity of pDAergic VTA neurons to GABA was significantly attenuated. There was no effect of TSA or SAHA on GABA sensitivity of pDAergic VTA neurons from saline-treated mice. In addition, ethanol withdrawal was associated with an increase in levels of HDAC2 and a decrease in histone (H3-K9) acetylation and levels of GABA (A- $\alpha$ I) R subunits in the VTA. Therefore, blockade of upregulation of HDAC2 by HDACi normalizes GABA hyposensitivity of pDAergic neurons developed during withdrawal after chronic ethanol treatment, which suggests the possibility that inhibition of HDACs can reverse ethanol-induced neuroadaptational changes in reward circuitry.

Neuropsychopharmacology (2013) 38, 1674-1684; doi:I0.1038/npp.2013.65; published online 3 April 20I3
\end{abstract}

Keywords: VTA; GABA; dopamine neurons; HDAC inhibitors; histone acetylation; alcohol withdrawal

\section{INTRODUCTION}

The mesolimbic dopamine (DA) system projects from the ventral tegmental area (VTA) to the nucleus accumbens (NAc), prefrontal cortex, basolateral amygdala, and to other corticolimbic structures (Albanese and Minciacchi, 1983; Oades and Halliday, 1987). Although drugs of abuse have distinct molecular targets, they all share the ability to increase DA levels in NAc (Luscher and Ungless, 2006; Arora et al, 2010). Acute administration of ethanol increases the firing rate of DA neurons, both in vitro and in vivo (Gessa et al, 1985; Brodie et al, 1990).

Chronic use of alcohol or drugs of abuse produces profound changes in the brain. Some of these changes may

*Correspondence: Dr MS Brodie, Department of Physiology and Biophysics, University of Illinois at Chicago, $835 \mathrm{~S}$ Wolcott, Room E-202, M/C 90I, Chicago, IL 606 I2-7342, USA, Tel: + I 3129962373 , Fax: + | 312996 |4|4, E-mail: mbrodie@uic.edu

Received 31 October 2012; revised I February 2013; accepted 21 February 2013; accepted article preview online 8 March 2013 be directly related to the process of addiction (Koob, 2003). We have shown previously that repeated ethanol treatment of $\mathrm{C} 57 \mathrm{Bl} / 6 \mathrm{~J}$ mice results in an increase in sensitivity to acute ethanol and a decrease in sensitivity to GABA-mediated inhibition (Brodie, 2002). Changes in the spontaneous frequency of firing of VTA neurons of rats and mice following a variety of ethanol treatment regimens have been demonstrated, but it is unknown whether GABA sensitivity has a role in this change in neuronal activity (Diana et al, 1992b; Shen and Chiodo, 1993; Bailey et al, 1998). The molecular basis of changes in GABA responses in the VTA induced by chronic alcohol exposure is not known.

In the recent years, the concept of epigenetics and alcohol abuse has provided new directions in the mechanistic approach to alcohol research (Pandey et al, 2008; Starkman et al, 2012). Epigenetic mechanisms include DNA methylation, histone modifications, and microRNA (Renthal and Nestler, 2008; Kalsi et al, 2009; Moonat et al, 2010). There is a growing interest in the possible functional consequences of covalent modification of the chromatin in the appearance and maintenance of behavioral changes, including the 
development and manifestation of addictive behavior (Sweatt, 2009; Renthal and Nestler, 2009a; Starkman et al, 2012). Modifications in chromatin architecture could underlie the long-lasting changes in neuronal gene expression and synaptic plasticity, and these changes ultimately could explain the processes involved in addictive behaviors (Renthal and Nestler, 2009a; Moonat et al, 2010). Recent studies have shown that when cocaine is administered at doses necessary to produce locomotor sensitization and conditioned place preference, histone hyperacetylation at specific brain areas relevant to the development of addictive behavior was observed (Kumar et al, 2005; Levine et al, 2005; Renthal and Nestler, 2008). Furthermore, the functional role of histone acetyltransferase (Levine et al, 2005) and histone deacetylase (HDAC) (Renthal et al, 2007) activities in the mechanism of action of psychostimulants has also been established, and is supported by experimental use of HDAC inhibitors (HDACi) (Kumar et al, 2005; Renthal et al, 2007; Kalda et al, 2007).

HDAC-induced chromatin remodeling in the amygdala has been implicated in alcohol dependence (Pandey et al, 2008). Anxiety-like behaviors that develop during withdrawal after chronic ethanol exposure in rats can be reversed by treatment with the HDACi trichostatin A (TSA). Rapid tolerance to anxiolytic effects of alcohol in rats can be reversed by TSA treatment, suggesting a role for amygdaloid HDAC-induced histone modifications in alcohol tolerance (Sakharkar et al, 2012). There are several HDAC isoforms, which are classified as Class I, II, III, and IV. The HDAC2 isoform, which belongs to Class I, has been shown to be involved in synaptic plasticity (Guan et al, 2009). The histone $\mathrm{H} 3$ is acetylated at the lysine nine position (H3-K9) by HDAC2, and it is this histone modification that has been associated with gene expression related to drug abuse and neural plasticity (Renthal and Nestler, 2008; Shibasaki et al, 2011). More recently, higher HDAC2 expression-induced deficits in histone H3-K9 acetylation and associated synaptic plasticity in the amygdala has been shown to be involved in alcoholdrinking behaviors (Moonat et al, 2013). However, the role of HDAC-induced histone modification in the reduction of GABA sensitivity in the VTA during alcohol withdrawal has not been examined. In the present study, we used extracellular recording from putative dopaminergic (pDAergic) VTA neurons in brain slices, and explored the effects of $\mathrm{HDACi}$ on the reduction in GABA responsiveness in the VTA induced by chronic ethanol administration in C57Bl/6J mice. In addition, we also investigated the effects of alcohol treatment and withdrawal on the levels of HDAC2, histone acetylation, and GABA-A $\alpha 1$ receptor (GABA $(A-\alpha 1) R$ ) subunit in the VTA of mice.

\section{MATERIALS AND METHODS}

\section{Animals}

C57BL/6J mice (4-6 weeks old) used in these studies were obtained from Jackson Labs (Bar Harbor, ME). All experimental procedures in mice were in strict accordance with the NIH Guidelines for the Care and Use of Laboratory Animals, and approved by the Animal Care Committee of the University of Illinois at Chicago.

\section{Chronic Ethanol Treatment}

All mice were treated for 3 weeks (21 days), with twice daily (morning (07:00-08:00 hour) and evening (15:00-17:00 hour)) intraperitoneal (ip) injections of either normal saline or $3.5 \mathrm{~g} / \mathrm{kg}$ ethanol $(20 \% \mathrm{w} / \mathrm{v}$ in normal saline). This injection paradigm has been used in other laboratories to produce tolerance to the behavioral effects of ethanol (Crabbe et al, 1982). To reduce the stress of twice daily ip injection, each mouse (control and ethanol-treated) was anesthetized lightly with halothane, immediately before each injection.

\section{Preparation of Brain Slices}

For the electrophysiological studies, mice were sacrificed at least $14 \mathrm{~h}$ after the last injection of either saline or ethanol. Brain slices containing the VTA were prepared from the subject animals, as previously described (Brodie et al, 1999a). Briefly, following rapid removal of the brain, the tissue was blocked coronally to contain the VTA and substantia nigra; the cerebral cortices and a portion of the dorsal mesencephalon were removed. The tissue block was mounted in the vibratome and submerged in chilled cutting solution. Coronal sections $(400-\mu \mathrm{m}$ thick) were cut and placed in $50 \mathrm{ml}$ polypropylene centrifuge tubes in aCSF with the addition of either $0.1 \%$ DMSO, $12.5 \mu \mathrm{M}$ TSA, or $3 \mu \mathrm{M}$ SAHA; both TSA and SAHA were dissolved in DMSO and were added to the aCSF in the centrifuge tubes such that the final DMSO concentration was $0.1 \%$. After $2 \mathrm{~h}$ incubation in one of these solutions, each slice then was placed onto a mesh platform in the recording chamber. Each slice was totally submerged in drug-free aCSF maintained at a flow rate of $2 \mathrm{ml} / \mathrm{min}$; the temperature in the recording chamber was kept at $35^{\circ} \mathrm{C}$. The composition of the aCSF in these experiments was (in $\mathrm{mM}$ ): $\mathrm{NaCl} 126, \mathrm{KCl} 2.5, \mathrm{NaH}_{2} \mathrm{PO}_{4} 1.24$, $\mathrm{CaCl}_{2}$ 2.4, $\mathrm{MgSO}_{4} 1.3, \mathrm{NaHCO}_{3} 26$, glucose 11 . The compo-

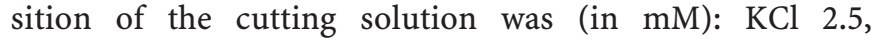
$\mathrm{CaCl}_{2} 2.4, \mathrm{MgSO}_{4} 1.3, \mathrm{NaHCO}_{3} 26$, glucose 11 , and sucrose 220. Both solutions were saturated with $95 \% \mathrm{O}_{2} / 5 \% \mathrm{CO}_{2}$ $(\mathrm{pH}=7.4)$. Recordings were made immediately, and were obtained up to $6 \mathrm{~h}$ after the slices were placed in the recording chamber.

\section{Cell Identification}

The VTA was clearly visible in the fresh tissue as a grey area medial to the darker substantia nigra, and separated from the nigra by white matter. Recording electrodes were placed in the VTA under visual control. pDAergic neurons have been shown to have distinctive electrophysiological characteristics (Grace and Bunney, 1984; Lacey et al, 1989). Only those neurons that were anatomically located within the VTA and that conformed to the criteria for pDAergic neurons established in the literature and in this laboratory (Lacey et al, 1989; Mueller and Brodie, 1989) were studied. These criteria include broad action potentials $(\geqslant 2.5 \mathrm{~ms}$, measured as the width of the bi- or tri-phasic waveform at the baseline), slow spontaneous firing rate $(0.5-5 \mathrm{~Hz})$, and a regular interspike interval. 


\section{Drug Administration}

Drugs were added to the aCSF by means of a calibrated infusion pump from stock solutions 100-1000 times the desired final concentrations. The addition of drug solutions to the aCSF was performed in such a way as to permit the drug solution to mix completely with aCSF before this mixture reached the recording chamber. Final concentrations were calculated from the aCSF flow rate, pump infusion rate, and concentration of drug stock solution. The small volume chamber (about $300 \mu \mathrm{l}$ ) used in these studies permitted the rapid application and washout of drug solutions. Typically, drugs reach equilibrium in the tissue after 2-3 min of application. GABA, ethanol, and most of the salts used to prepare the extracellular media were purchased from Sigma Aldrich Corporation (St Louis, MO). Suberoylanilide hydroxamic acid (SAHA) and TSA were obtained from Selleck Chemicals (Houston, TX).

\section{Extracellular Recording}

Extracellular recording electrodes were made from 1.5-mm diameter glass tubing with filament and were filled with $0.9 \% \mathrm{NaCl}$. Tip resistance of the microelectrodes ranged from 2 to $5 \mathrm{M} \Omega$. A Fintronics amplifier was used in conjunction with an IBM-PC-based data acquisition system (ADInstruments, Colorado Springs, CO, USA). Offline analysis was used to calculate, display, and store the frequency of firing 1-min intervals. Firing rate was determined before and during drug application. Firing rate was calculated over 1-min intervals before administration of drugs and during the drug effect; peak drug-induced changes in firing rate were expressed as the percentage change from the control firing rate according to the formula $((\mathrm{FRD}-\mathrm{FRC}) / \mathrm{FRC}) \times 100$, where $\mathrm{FRD}$ is the firing rate during the peak drug effect and FRC is the control firing rate. The change in firing rate thus is expressed as a percentage of the initial firing rate, which controls for small changes in firing rate that may occur over time. This formula was used to calculate both excitatory and inhibitory drug effects. Peak excitation was defined as the peak increase in firing rate produced by the drug greater than the pre-drug baseline. Inhibition was defined as the lowest firing rate below the pre-drug baseline.

\section{Gold Immunolabeling Histochemical Procedure}

Mice were subjected to repeated treatment with either ethanol or saline injections, as described above. Three groups of mice were used: saline-treated mice that received their last injection at least $14 \mathrm{~h}$ earlier (control), ethanoltreated mice that received their last ethanol injection at least $14 \mathrm{~h}$ earlier (withdrawal), and ethanol-treated mice that received an ethanol injection $1 \mathrm{~h}$ before sacrifice (ethanol). Blood was taken to assess ethanol concentration using an Analox Alcohol Analyzer (Analox Instruments, Lunenberg, MA). Each mouse was anesthetized and then perfused intracardially with ice-cold normal saline (30-50 ml), followed by $4 \%$ paraformaldehyde $(30-50 \mathrm{ml}$; $\mathrm{PFA}$ ) prepared in $0.1 \mathrm{M}$ phosphate buffer ( $\mathrm{pH}$ 7.4). Brains were removed and placed in PFA for $20 \mathrm{~h}$ at $4{ }^{\circ} \mathrm{C}$. Then, brains were soaked sequentially in 10,20 , and $30 \%$ sucrose solutions (dissolved in phosphate buffer, $\mathrm{pH}$ 7.4). Brains were then frozen and stored at $-80^{\circ} \mathrm{C}$ until used for the gold immunolabeling with antibodies to HDAC2 (MBL, Woburn, MA), acetylated histone H3-K9 (Millipore, Billerica, MA), and GABA (A- $\alpha 1$ ) $\mathrm{R}$ (Abcam, Cambridge, MA), as described previously (Pandey et al, 2008; Sakharkar et al, 2012). Briefly, $20 \mu \mathrm{m}$ coronal cryostat sections were cut and placed in $0.01 \mathrm{M}$ phosphate-buffered saline (PBS) for washing, followed by sequential incubations in RPMI (Invitrogen, Grand Island, NY), $10 \%$ normal goat serum (Vector Labs, Burlingame, $\mathrm{CA}$ ), and $1 \%$ bovine serum albumin in PBST for $30 \mathrm{~min}$ each. Sections were then incubated for $16-18 \mathrm{~h}$ at room temperature in antibodies against HDAC2 $(1: 200)$, acetylated histone H3-K9 $(1: 500)$, or GABA (A- $\alpha 1) \mathrm{R}(1: 200)$. Sections were further washed in PBS and incubated in gold particle-conjugated anti-rabbit secondary antibody $(1: 200)$ for $1 \mathrm{~h}$ (Nanoprobes, Yaphank, NY), and were developed using silver enhancement solution (Ted Pella, Redding, CA). Gold-immunolabeled HDAC2, acetylated H3-K9, and GABA $(\mathrm{A}-\alpha 1) \mathrm{R}$ were quantified using the image analysis program at $100 \times$ magnification, as described previously (Pandey et al, 2008; Sakharkar et al, 2012). Immunogold particles in the VTA region in each of three adjacent brain sections (9-11 total object fields) were quantified; values were averaged for each animal and results were represented as mean \pm SEM of the number of immunogold particles per $100 \mu \mathrm{m}^{2}$ area.

\section{Statistical Analysis}

Averaged numerical values were expressed as the mean \pm SEM. Data were analyzed by using one- or two-way analysis of variance (ANOVA) followed by Tukey's post hoc comparisons of means. A value of $p<0.05$ was considered to be significant.

\section{RESULTS \\ Electrophysiology: VTA Neuron Characteristics}

A total of 112 pDAergic VTA neurons from 25 mice were used in the electrophysiological portion of this study. The firing rate of these neurons ranged from 0.57 to $4.2 \mathrm{~Hz}$, with an overall mean firing rate of $2.06 \pm 0.11 \mathrm{~Hz}$. All of the neurons tested had regular firing rates and were inhibited by GABA. Cells that did not return to within $10 \%$ of the pre-drug firing rate during washout were not used.

For slices treated with DMSO or HDACi, recordings were made in up to eight neurons per slice, with an average number of cells per slice of $4.9 \pm 0.42$. There was a significant difference in the baseline frequency of firing rate of pDAergic VTA neurons among these groups (one-way ANOVA, $\mathrm{F}_{5,99}=2.83 ; p<0.02$ ), with Tukey's mean comparison indicating a significant difference between only the ethanol injected, DMSO-treated (E-DMSO) cells and the ethanol-injected, TSA-treated (E-TSA) cells (Tukey's post hoc test, $p<0.05$ for E-DMSO and E-TSA groups, $p>0.05$ for comparisons of all other groups) (Table 1). 
Table I Baseline Firing Rates of pDAergic VTA Neurons Under the Various Treatment Conditions

\begin{tabular}{lcc}
\hline Condition & Mean baseline firing rate $(\mathrm{Hz})$ & Number of cells \\
\hline Saline-DMSO & $2.24 \pm 0.24$ & 18 \\
Ethanol_DMSO & $1.86 \pm 0.22$ & 17 \\
Saline-TSA & $2.78 \pm 0.31$ & 16 \\
Ethanol-TSA & $2.83 \pm 0.21$ & 17 \\
Saline-SAHA & $2.64 \pm 0.18$ & 17 \\
Ethanol_SAHA & $2.13 \pm 0.22$ & 20 \\
\hline
\end{tabular}

\section{Electrophysiology: GABA Sensitivity}

Brain slices containing the VTA were taken from salinetreated and ethanol-treated mice, and subjected to one of several incubation conditions: in aCSF with DMSO (final DMSO concentration $0.1 \%)$; in aCSF with TSA $(12.5 \mu \mathrm{M})$, or in a CSF with SAHA $(3 \mu \mathrm{M})$. Once the 2 -h incubation was complete, the slices were removed from the incubation chambers and placed in the recording chambers, where they were superfused with drug-free aCSF, as described in the Materials and Methods section.

Each recorded neuron was tested in the following protocol: a single concentration of GABA (either 50, 100, 200 , or $500 \mu \mathrm{M}$ ) that was superfused over the slices for $4 \mathrm{~min}$ followed by washout period of 8 min with normal aCSF or until the baseline was recovered. Upon recovery, the next higher GABA concentration was tested similarly, and this procedure was repeated until all four GABA concentrations were tested. Typical responses to GABA are shown in Figure 1 .

\section{Incubation with DMSO: Ethanol Withdrawal vs Saline Treatment}

For the population of cells from mice treated with saline and incubated with DMSO, GABA $(50-500 \mu \mathrm{M})$ produced inhibition of firing in a concentration-dependent manner (Figure 1a, Figure $2 \mathrm{a}(\bullet)$ ); this is consistent with our previous report (Brodie, 2002). Overall, there was a significant effect of GABA concentration, indicating overall a concentration-dependent inhibition of firing produced by GABA (two-way ANOVA, $\mathrm{F}_{3,430}=95.8, p<0.01$, Tukey's post hoc test, $p<0.05$ ).

Also consistent with our previous report (Brodie, 2002), withdrawal from the repeated treatment with ethanol in mice produced a decrease in the sensitivity to GABA in pDAergic VTA neurons. In comparison with pDAergic VTA neurons from saline-treated mice incubated with DMSO vehicle, there was a significant reduction in GABA inhibition (Figure 1b, Figure 2a).

As all groups were analyzed together using a two-way ANOVA test, we could compare the sensitivity of all groups with each other. The GABA responses of pDAergic VTA neurons from ethanol-withdrawn mice and incubated with DMSO vehicle differed from the GABA responses in all other groups, and none of the other groups differed from each other (two-way ANOVA, $\mathrm{F}_{5,430}=13.5, p<0.01$, Tukey's post hoc test, $p<0.05$ for EtOH-DMSO group versus all other groups).

\section{Incubation with TSA and SAHA: Ethanol Withdrawal $v s$ Saline Treatment}

For pDAergic VTA neurons from saline-treated mice and incubated with TSA (Figure 2b), the response to GABA was not different from pDAergic VTA neurons from salinetreated mice that were incubated with DMSO vehicle (as above two-way ANOVA with Tukey's post hoc test, $p>0.05$ ).

For pDAergic VTA neurons from ethanol-withdrawn mice and incubated with TSA (Figure $2 b(\square)$ ), the response to GABA was not different from pDAergic VTA neurons from saline-treated mice that were incubated with TSA (as above, two-way ANOVA with Tukey's post hoc test, $p>0.05)$.

For pDAergic VTA neurons from saline-treated mice and incubated with SAHA (Figure 2C), the response to GABA was not different from pDAergic VTA neurons from salinetreated mice that were incubated with DMSO vehicle (as above, two-way ANOVA with Tukey's post hoc test, $p>0.05)$.

The pDAergic VTA neurons from ethanol-withdrawn mice and incubated with SAHA (Figure $2 c(\nabla)$ ), the response to GABA was not different from pDAergic VTA neurons from saline-treated mice that were incubated with SAHA (as above, two-way ANOVA with Tukey's post hoc test, $p>0.05)$.

\section{Effects of Ethanol Treatment and its Withdrawal on Protein Levels of HDAC2 and Acetylated Histone H3 in the VTA}

As noted in the Materials and Methods, three groups of mice were used in the gold immunolabeling experiments: saline-treated mice (control), ethanol-treated mice that received their last ethanol injection at least $14 \mathrm{~h}$ earlier (withdrawal), and ethanol-treated mice that received an ethanol injection $1 \mathrm{~h}$ before sacrifice (ethanol). The blood ethanol levels in mice $1 \mathrm{~h}$ after ethanol injections were $291.6 \pm 15.1 \mathrm{mg} / \mathrm{dl}(n=6)$. This can be contrasted with levels reported in ethanol-naive $\mathrm{C} 57 \mathrm{BL} / \mathrm{cCrgl}$ mice injected ip with a similar dose of ethanol $(3.32 \mathrm{~g} / \mathrm{kg})$, which produced a mean concentration of $473 \mathrm{mg} / 100 \mathrm{ml}$ of blood at waking, and a mean blood ethanol concentration of $286 \mathrm{mg} / 100 \mathrm{ml}$ $3 \mathrm{~h}$ after injection (Kakihana et al, 1966).

As histone deacetylase inhibitors (HDACi) appeared to reverse the effect of repeated ethanol treatment on responsiveness to GABA in the electrophysiological experiments, we assessed whether there was a change in HDAC2 and acetylated histone H3-K9 protein levels during withdrawal after repeated ethanol exposure. The photomicrographs in Figure 3 illustrate positive cells for acetylated $\mathrm{H} 3-\mathrm{K} 9$ and $\mathrm{HDAC} 2$ proteins, and quantified data in terms of the number of immunogold particles for acetylated H3-K9 and HDAC2 in the VTA are shown in Figure 4. It was found that ethanol withdrawal produced significant $(p<0.001)$ reductions in acetylation of H3-K9 in the VTA as compared with controls. When ethanolwithdrawn mice were treated with an ethanol injection $1 \mathrm{~h}$ before sacrifice, their levels of acetylated H3-K9 were 

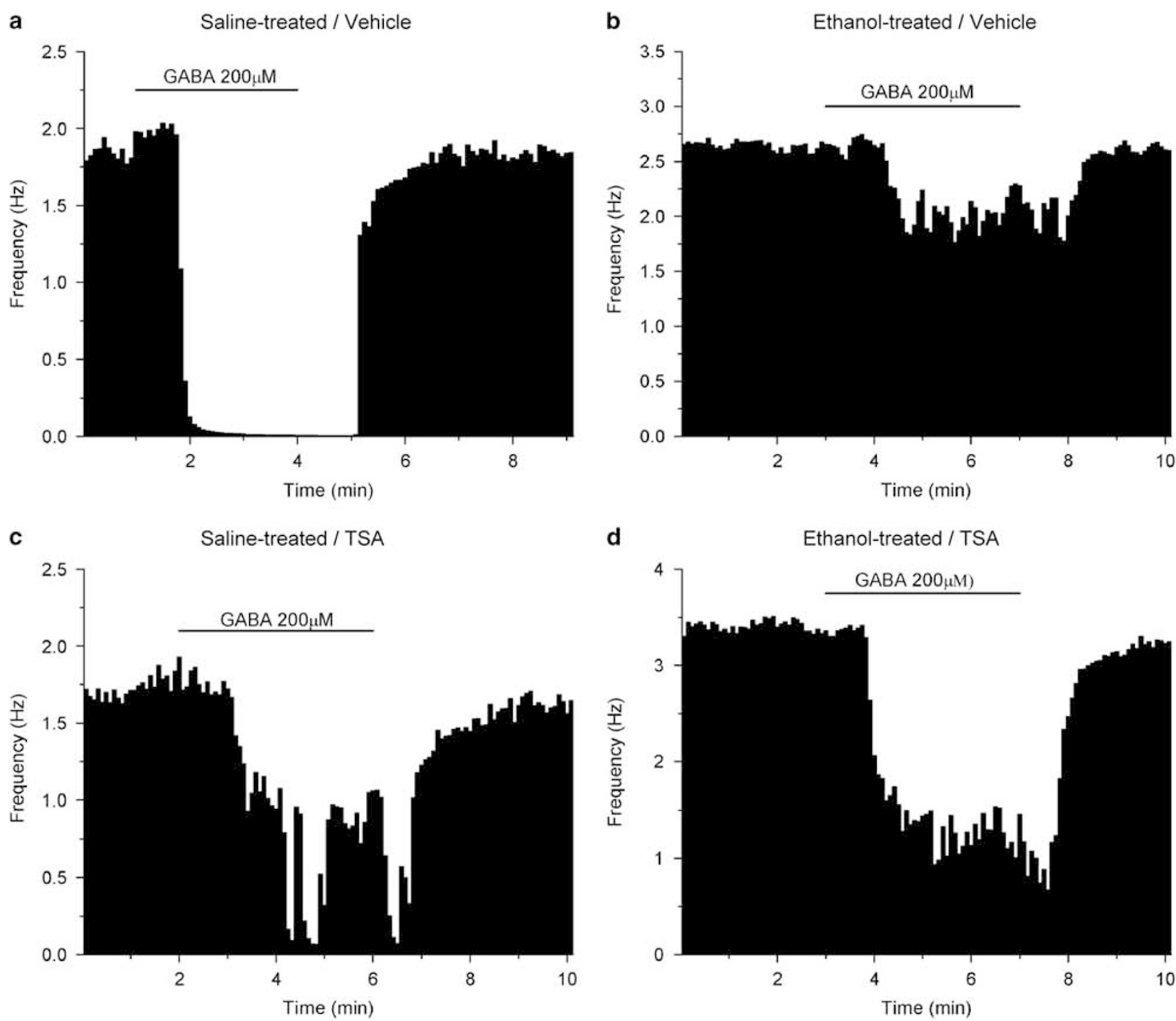

d Ethanol-treated / TSA

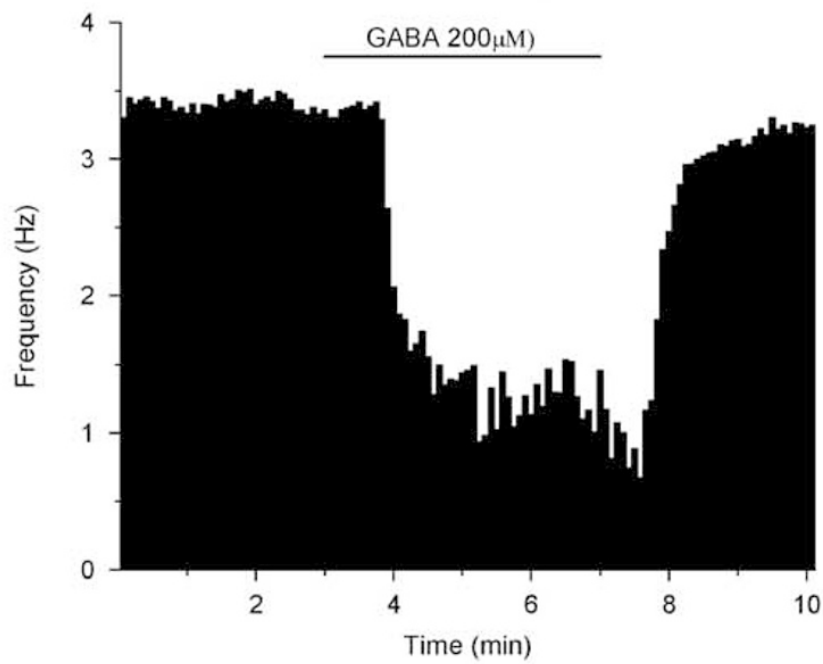

e

Saline-treated / SAHA

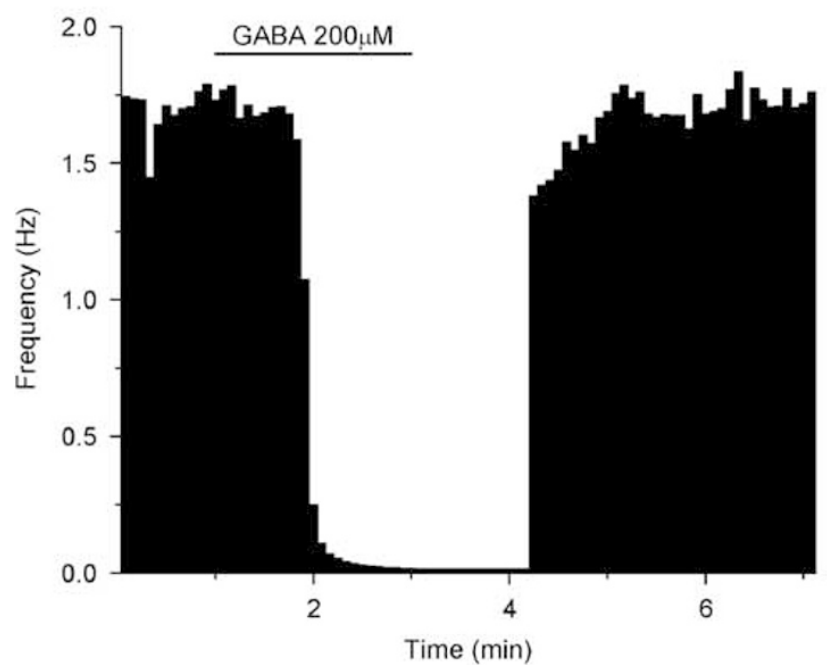

$\mathbf{f}$

Ethanol-treated / SAHA

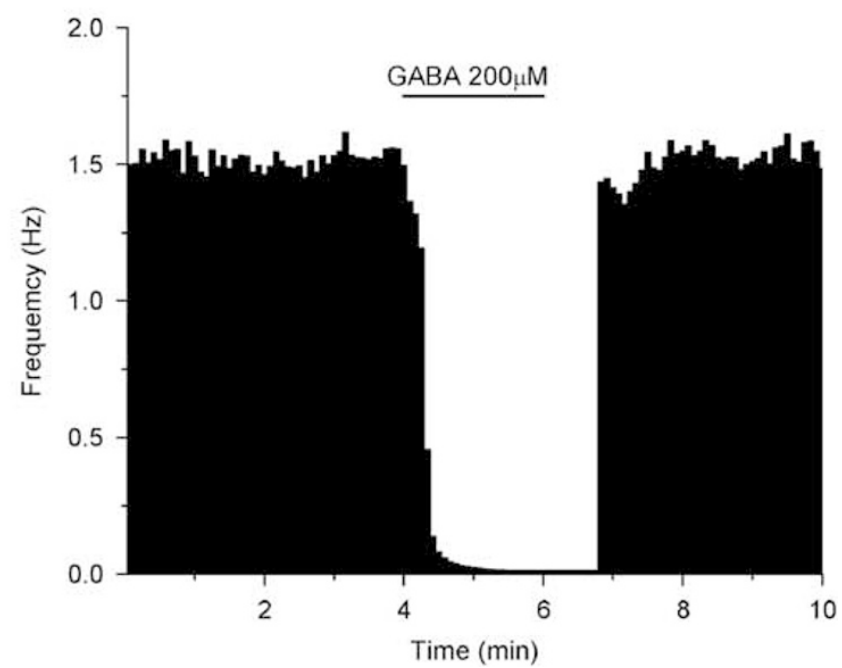

Figure I Single neurons: effects of $200 \mu \mathrm{M}$ GABA. Each figure represents the firing rate of a single neuron of the VTA over time. Vertical bars are proportional to the firing rate over a 5 -s interval, horizontal bars represent the duration of application of GABA (200 $\mu$ M). Neurons were recorded in brain slices from mice treated with saline $(a, c, e)$ or ethanol (b, d, f). Slices were incubated with DMSO $(a, b)$, TSA (c, d), or SAHA (e, f). Addition of $200 \mu$ M GABA to the extracellular medium resulted in maximum reductions of firing in these neurons of (a) $-99.6 \%$, (b) - 22.7\%, (c) - 76.9\%, (d) - 70.0\%, (e) $-99.2 \%$, (f) $-98.5 \%$. 
a

GABA Concentration $(\mu \mathrm{M})$

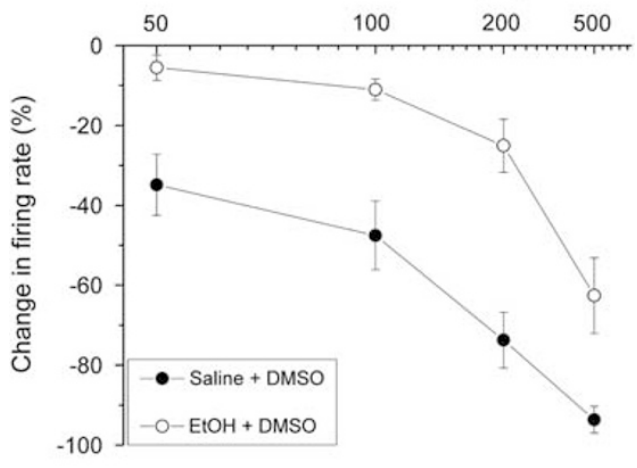

b

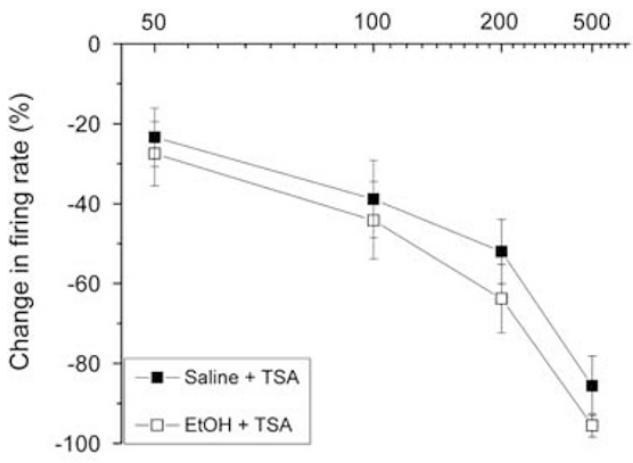

C

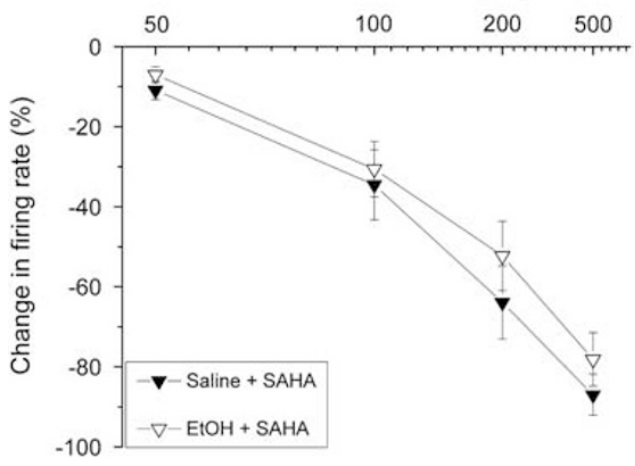

Figure 2 Pooled responses: effects of GABA. Pooled concentrationresponse curves for pDAergic VTA neurons from brain slices from mice treated with repeated injections of either saline (filled symbols) or ethanol (open symbols). Slices were incubated for $2 \mathrm{~h}$ with $0.1 \%$ DMSO (a), $12.5 \mu \mathrm{M}$ TSA (b), or $3 \mu \mathrm{M}$ SAHA (c). (a) Incubation in DMSO (vehicle controls): slices from saline-treated $(\mathbf{O})$ or ethanol-treated mice $(O)$; (b) incubation in TSA: slices from saline-treated $(\boldsymbol{\square})$ or ethanol-treated mice $(\square)$; (c) incubation in SAHA: slices from saline-treated $(\boldsymbol{\nabla})$ or ethanoltreated mice $(\nabla)$.

similar to control levels (Figures 3 and 4). Conversely, HDAC2 protein expression was upregulated in the VTA of the ethanol-withdrawn animals as compared with that of saline-treated and ethanol (ethanol injection $1 \mathrm{~h}$ before sacrifice) groups (bottom panels of Figures 3 and 4). Immunolabeling in the VTA for the withdrawal group differed from the other two groups for both HDAC2 (one-way ANOVA; $\mathrm{F}_{2,15}=32.77, \quad p<0.001 ; n=6$ ) and H3-K9 acetylation (one-way ANOVA, $\mathrm{F}_{2,15}=25.12$, $p<0.001 ; n=6)$.
Effects of Ethanol Treatment and its Withdrawal on Protein Levels of the $\alpha 1$ Subunit of GABA-A Receptors

The hyposensitivity to GABA during ethanol withdrawal could be due to reduction in GABA receptors. Figure 5 shows that the inhibition of DA VTA neurons by the concentrations of GABA used in the present study were mediated by the activation of GABA-A receptors. GABA $(50-500 \mu \mathrm{M})$ was tested on pDAergic VTA neurons from naive $\mathrm{C} 57$ mice in the absence and presence of the GABA-B receptor antagonist CGP35348 $(1 \mu \mathrm{M})$. There was no significant difference in the response to GABA whether CGP35348 was present or not (two-way ANOVA, $\mathrm{F}_{1,51}=$ $1.4 \mathrm{E}-5, p>0.99)$, indicating that GABA-induced inhibition over the concentration range tested is primarily because of the action at GABA-A receptors.

Next, we examined the changes in one GABA-A receptor subunit that has been shown to be reduced by chronic ethanol treatment: the $\alpha 1$ subunit (Kumar et al, 2003). The photomicrograph in Figure 6a illustrates GABA (A- $\alpha 1)$ R-positive cells in the VTA of various group of C57 mice treated according to the repeated injection protocol. The Figure $6 \mathrm{~b}$ shows the mean number of immunogold particles under the same conditions as in Figures 3 and 4. The protein levels of GABA $(A-\alpha 1)$ R were downregulated in the VTA during withdrawal, and significantly $(p<0.001)$ differed from the groups treated with saline or chronic ethanol, with an ethanol injection $1 \mathrm{~h}$ before sacrifice (one-way ANOVA, $\mathrm{F}_{2,15}=35.25, p<0.001 ; n=6$ ).

\section{DISCUSSION}

The novel findings of present study demonstrate that decreased GABA responses in DA VTA neurons induced by 3 weeks of repeated ethanol administration can be reversed by a relatively brief $(2 \mathrm{~h})$ incubation with the HDACi, TSA, or SAHA. Complementary and related immunohistochemical examination of acetylated histone H3-K9 and HDAC2 indicates that withdrawal from repeated ethanol increases HDAC2 protein levels and decreases histone acetylation (acetylated H3-K9) in the VTA. The reversal by SAHA or TSA of the effect of repeated ethanol on sensitivity to GABA suggests a new paradigm for treatment of alcohol-induced brain changes; this goes beyond pharmacological amelioration of symptoms and approaches a class of therapy that normalizes neurotransmission in the alcoholic brain. This is further supported by recent findings that TSA treatment during withdrawal after chronic ethanol exposure corrected the deficits in H3-K9 acetylation by blocking the upregulation of HDAC activity in the amygdala and prevented the development of anxietylike behaviors in rats (Pandey et al, 2008). Furthermore, it has been shown that knockdown of HDAC2 in the central nucleus of amygdala attenuated alcohol intake in alcoholpreferring rats (Moonat et al, 2013). The current report is the first of which we are aware demonstrating that in vitro administration of an HDACi can reverse the effects of in vivo ethanol treatment. Some epigenetic changes in the VTA during withdrawal from chronic ethanol may be related to an increased expression of HDAC2, and clearly there is sufficient transcription and turnover in the brain slice preparation over a 2-h period to reverse 

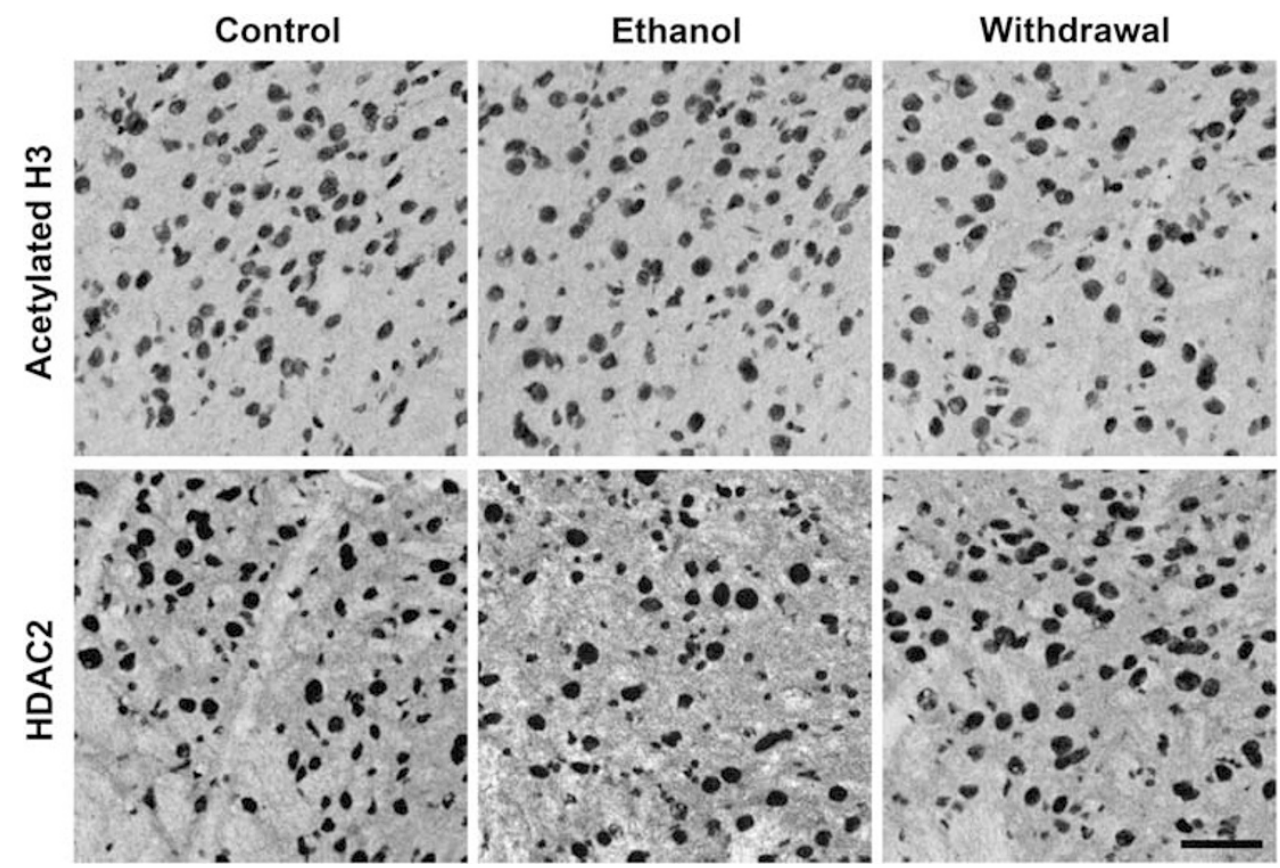

Figure 3 Representative photomicrographs (scale bar $=40 \mu \mathrm{m}$ ) showing acetylated histone H3-K9 (top panel) and HDAC2 (bottom panel) gold immunolabeling in the VTA of repeated saline treatment (Control), repeated ethanol treatment with last ethanol injection I h before sacrifice (Ethanol), and repeated ethanol treatment with last ethanol injection $>14 \mathrm{~h}$ before sacrifice (Withdrawal).

withdrawal-induced GABA hyposensitivity, once HDAC is inhibited by TSA or SAHA.

Acute ethanol exposure excites VTA DA neurons directly (Brodie et al, 1999b); however, other factors may enhance ethanol-induced excitation of DA VTA neurons. For example, ethanol can hyperpolarize the GABA-containing neurons of the VTA (Gallegos et al, 1999; Xiao and Ye, 2008) and can influence NMDA receptor-mediated excitation of VTA DA neurons (Stobbs et al, 2004). Chronic ethanol is likely to affect various ethanol-sensitive properties differently, resulting in apparent increases or decreases in the effects of ethanol. This idea is supported by evidence from our laboratory (Brodie, 2002) that DA VTA neurons from mice subjected to repeated ethanol treatment were more sensitive to the excitatory action of ethanol and less sensitive to inhibition by GABA, but responsiveness to NMDA was unaffected. Chronic ethanol and subsequent withdrawal may have more profound effects on GABA neurons of the VTA; chronic exposure to ethanol enhances the baseline activity of GABA neurons and induces tolerance to ethanol inhibition of the firing rate of these neurons (Gallegos et al, 1999). In contrast, tolerance has not been observed to ethanol-induced excitation of DA VTA neurons after chronic ethanol treatment (Diana et al, 1992a; Brodie, 2002). As we report here and have reported previously (Brodie, 2002), there is a decrease in the response of pDAergic VTA neurons in vitro to exogenously applied GABA during ethanol withdrawal. Furthermore, consistent with the previous studies (Brodie, 2002), there was no significant difference in the basal spontaneous firing between the ethanol exposed and control groups under each condition, although there was a difference between two of the groups.
The phenomenon of reduced sensitivity to GABA could be attributed to the postsynaptic adaptive changes in the GABA receptor subunit composition during withdrawal from chronic ethanol. Although activation of GABA-B receptors can cause inhibition of pDAergic VTA neurons (Lacey et al, 1988; Mueller and Brodie, 1989), data above indicate that the concentrations of GABA used in the present study caused inhibition by GABA-A receptor activation. It has been shown that there is a shift in the $\alpha$-subunit composition in the mesolimbic system of rat following chronic ethanol administration (Papadeas et al, 2001; Liang et al, 2007). Other proposed mechanisms for chronic ethanol-induced GABA-A receptor adaptations include alterations in gene expression, post-translational modifications, synaptic localization, and intracellular signaling (Kumar et al, 2004). Increased internalization of GABA (A- $\alpha 1) \mathrm{R}$ subunit has been demonstrated in cerebral cortex after chronic ethanol consumption (Kumar et al, 2003). No change in the GABA $(A-\alpha 1) R$ subunit was observed in the VTA in rats chronically drinking alcohol, but levels during withdrawal were not examined (Papadeas et al, 2001). Here we demonstrated that withdrawal, not ethanol exposure per se, produced downregulation of GABA $(\mathrm{A}-\alpha 1) \mathrm{R}$ protein levels in the VTA of mice. Certain combinations of GABA-A receptor subunits form GABA-A receptors that respond to GABA with lower efficacy. For example, $\alpha 4 \beta 1 \gamma 2$ GABA-A receptors respond to GABA with lower efficacy than $\alpha 1 \beta 1 \gamma 2$ GABA-A receptors (Whittemore et al, 1996). Although another group has shown no change in $\alpha 4$ subunit following 14-day ethanol consumption (Papadeas et al, 2001), it is known that different treatment regimens can produce different effects on GABA subunits (Matthews et al, 1998), and there may be differences in 

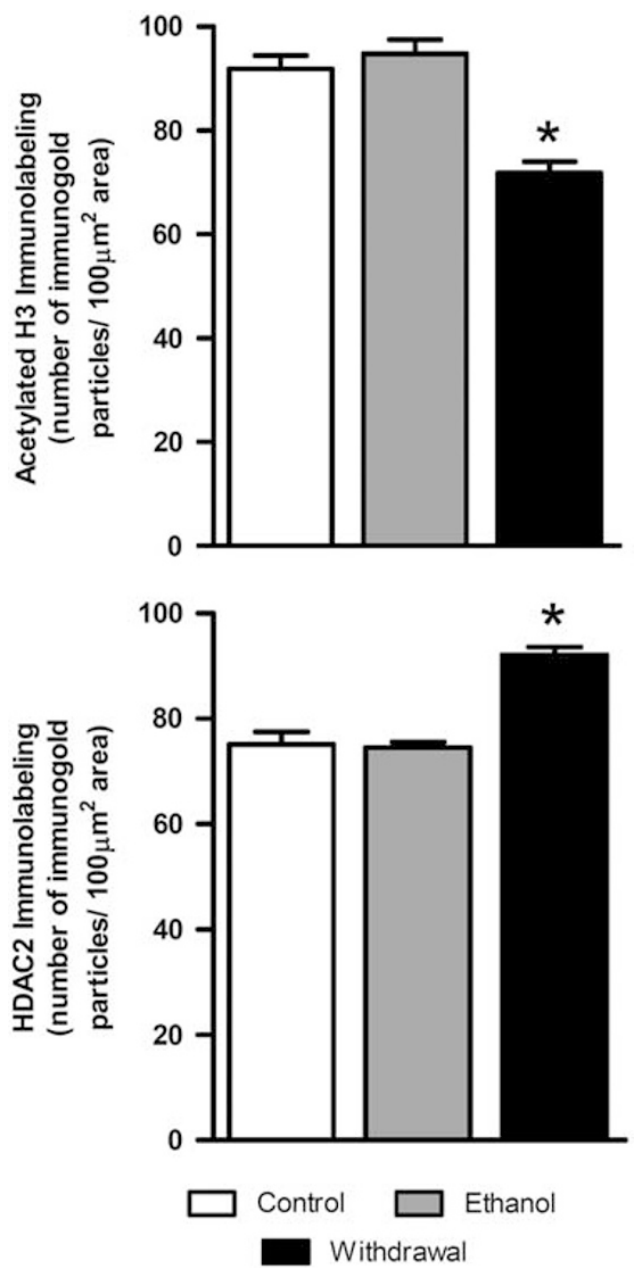

Figure 4 Bar diagrams showing the differences in the acetylated $\mathrm{H} 3(\mathrm{H} 3-$ K9) and HDAC2 protein levels in the VTA of repeated saline treatment (Control, $n=6$ ), repeated ethanol treatment with last ethanol injection I $\mathrm{h}$ before sacrifice (Ethanol, $n=6$ ), and repeated ethanol treatment with last ethanol injection $>14 \mathrm{~h}$ before sacrifice (Withdrawal, $n=6$ ). There was a significant decrease in acetylated $\mathrm{H} 3(* p<0.00 \mathrm{I})$ and a reciprocal increase in the levels of HDAC2 $\left({ }^{*} p<0.00 \mathrm{I}\right)$ in the VTA of mice in withdrawal from ethanol (Withdrawal) compared with that of saline-treated controls (Control) or to ethanol-treated mice that received an ethanol injection I h before sacrifice (Ethanol).

GABA receptor subunits during withdrawal that are not seen during ethanol treatment. The $\beta 3$ subunit may be particularly important for GABA-A receptor trafficking and control of responsiveness to GABA (Parker et al, 2011). Furthermore, in humans, the genes encoding the GABA-A receptor subunits are clustered in several chromosomal regions, and the chromosome 4 clusters of genes are likely to be important in addiction and anxiety and may be vulnerable to epigenetic effects in early development (Enoch et al, 2009).

The focus of the electrophysiological portion of the present study was to assess the control of ethanol withdrawal-induced GABA hyposensitivity by HDAC by incubating the slices with HDACi. We observed that inhibition of HDACs abolished the ethanol withdrawalinduced changes in GABA sensitivity of pDAergic VTA neurons in the VTA. It seems plausible that decreases in

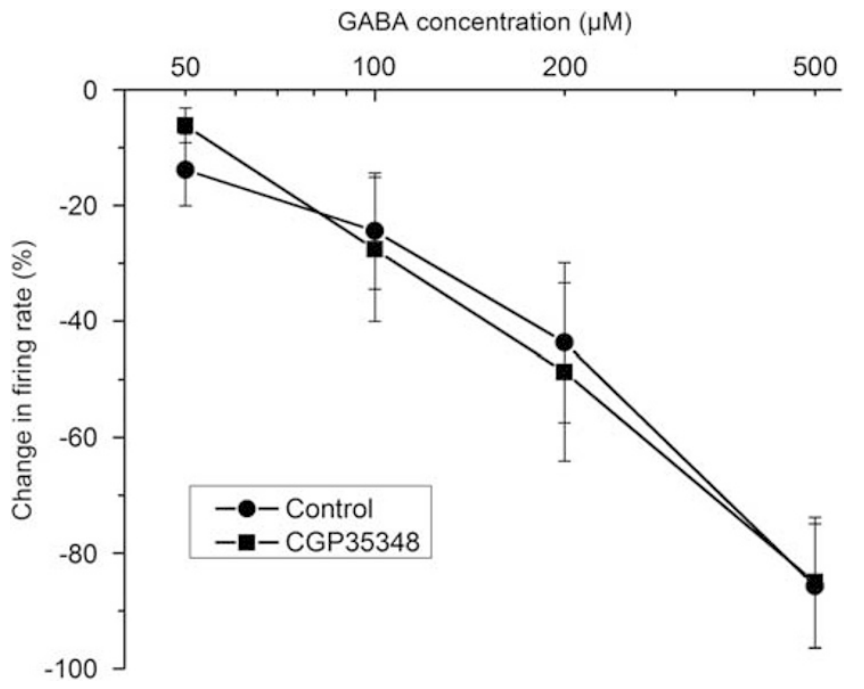

Figure 5 The effects of GABA-B antagonist CGP35348 on GABAinduced inhibition of pDAergic VTA neurons. Pooled concentrationresponse curves for responses to GABA of pDAergic VTA neurons from brain slices from mice in the absence $(\mathbf{)})$ or presence $(\boldsymbol{\square})$ of CGP35348 $(\mathrm{I} \mu \mathrm{M})$. GABA (50-500 $\mu \mathrm{M})$ was applied to each neuron, then CGP35348 was added to the medium and the same concentrations of GABA were tested. There was no significant difference in response to GABA between the groups (two-way ANOVA, $\mathrm{F}_{1,51}=1.4 \mathrm{E}-5, \mathrm{p}>0.99$ ).

histone acetylation in VTA induced by upregulation of HDAC2 produces the adaptive changes in the GABA-A receptors, accounting for the GABA hyposensitivity of pDAergic neurons that we observed during ethanol withdrawal. Note that no HDACi was present during the assessment of GABA inhibition; a 2-h incubation period preceded the placement of the brain slices in the recording chambers, and no HDACi was present in the superfusion medium. As the recordings were obtained over a 5-7-h period after the slices were removed from the HDACicontaining medium, it is unlikely that any significant amount of HDACi was present during the recordings. This suggests that the 2-h incubation produced a sustained change in GABA responsiveness due to a persistent biochemical change, rather than a direct interaction of the HDACi with GABA receptors during the GABA administration in the electrophysiology experiments. Furthermore, treatment with TSA or SAHA did not alter the overall GABA sensitivity of VTA neurons from saline-treated mice. These results suggest a possibility for HDAC-induced histone deacetylation as a mechanism for the changes in GABA sensitivity in the VTA induced by repeated ethanol administration.

The ability of HDACi to reverse changes in GABA sensitivity observed in VTA neurons from ethanol-treated mice in withdrawal suggests a change in HDAC activity that is induced by repeated ethanol treatment. We observed that HDAC2 levels were significantly elevated in the ethanoltreated mice at a time equivalent to the time period during which recordings would have been made. We do not know whether other HDAC isoforms were similarly increased during withdrawal after repeated ethanol treatment. Correlated with the HDAC2 increase was a complementary decrease in histone H3-K9 acetylation and expression of 

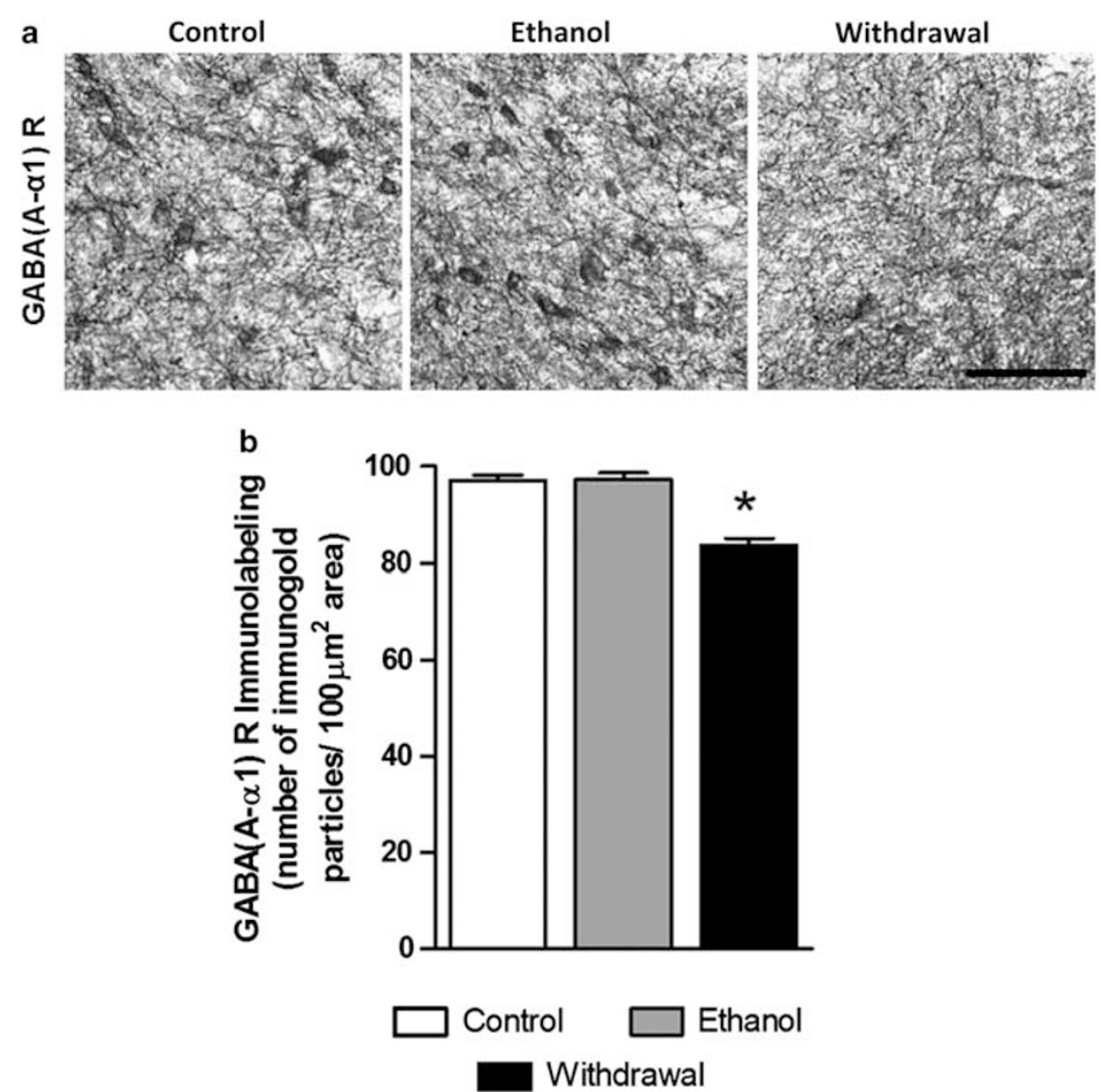

Figure 6 (a) Representative low-magnification photomicrographs (scale bar $=40 \mu \mathrm{m}$ ) of gold immunolabeling of GABA (A- $\alpha$ I) R subunit in the VTA of repeated saline treatment (Control), repeated ethanol treatment with last ethanol injection I h before sacrifice (Ethanol), and repeated ethanol treatment with last ethanol injection $>14 \mathrm{~h}$ before sacrifice (Withdrawal). (b) Bar diagrams showing the differences in the protein levels of GABA (A- $\alpha \mathrm{I}$ ) R subunit in the VTA of repeated saline treatment (Control, $n=6$ ), repeated ethanol treatment with last ethanol injection I $h$ before sacrifice (Ethanol, $n=6$ ), and repeated ethanol treatment with last ethanol injection $>14 \mathrm{~h}$ before sacrifice (Withdrawal, $n=6$ ). There was a significant decrease in $G A B A(A-\alpha I) R$ subunit $(* 20.00 \mathrm{I})$ in the VTA of mice in withdrawal from ethanol (Withdrawal) compared with that of saline-treated controls (Control) or to ethanoltreated mice.

GABA $(A-\alpha 1)$ R subunit in the VTA; although there may have been changes in other HDAC isoforms, the overall effect of withdrawal after repeated ethanol was to produce a significant decrease in histone $\mathrm{H} 3$ acetylation. Interestingly, when ethanol was present, the levels of HDAC2 and histone acetylation as well as GABA $(\mathrm{A}-\alpha 1) \mathrm{R}$ were not different from controls. This suggests that these changes in VTA may be related to the withdrawal state, and are rapidly reversed by ethanol exposure. As the VTA has been linked to reward/ reinforcement and craving, the change in HDAC activity during withdrawal observed in the present study might be linked to withdrawal-induced craving (Lopez and Becker, 2005; Enoch, 2008). Future studies will be needed to determine whether in vivo HDACi modulate increases in HDAC2 and concomitant decreases in histone acetylation specific to various GABA-A receptor subunits, and whether this treatment could reverse changes in GABA responsiveness in the VTA during withdrawal after chronic ethanol exposure.

Neuroadaptational changes in the histone acetylation and HDAC activity in the amygdala induced during withdrawal after chronic ethanol have been reported to be reversed or prevented by TSA. The few studies performed with respect to HDAC-induced histone deacetylation in response to alcohol administration have focused on the forebrain (Pandey et al, 2008; Moonat et al, 2013; Sakharkar et al, 2012). In particular, changes in histone acetylation associated with drug abuse have centered on the amygdala (Pandey et al, 2008; Sakharkar et al, 2012) and the NAc (Renthal and Nestler, 2009b). One group has observed increases in acetylated histone $\mathrm{H} 3$ protein in midbrain during a single withdrawal from a 9-day course of ethanol vapor inhalation in male ddY mice (Shibasaki et al, 2011); the differences between that and the present study may be related to brain region specificity and differences in duration and treatment paradigm of ethanol. Nonetheless, the present study is the first to examine the actions of HDACi on ethanol-induced changes in GABA electrophysiological responses in the VTA. The observation that HDACi appears to restore GABA sensitivity in the VTA suggests that ethanol-induced changes in histone acetylation may be the mechanism for abnormal reward circuitry occurred during ethanol exposure. It is known that experience with alcohol increases alcohol self-administration and alcohol seeking (Lopez and Becker, 2005; Griffin et al, 2009). As the VTA is associated with the rewarding/reinforcing 
effects of alcohol and other drugs of abuse, it is provocative to speculate on the possibility that inhibition of HDAC may produce a decrease in drug-seeking behavior related to reward and reinforcement.

\section{ACKNOWLEDGEMENTS}

This work was supported by the National Institute on Alcohol Abuse and Alcoholism Grants AA-016690, AA-019971 (NADIA project), and by the Department of Veterans Affairs (Merit Review Grant-101BX000143; Research Career Scientist award) to SCP, and by the National Institute on Alcohol Abuse and Alcoholism Grants AA-05846 and AA09125 to MSB.

\section{DISCLOSURE}

Dr Pandey reports that a US patent application entitled 'Histone acetyl transferase activators and histone deacetylase inhibitors in the treatment of alcoholism' (serial number 60/848237 filed on 29 September, 2006), which is directed to a proposed method for reducing symptoms related to alcohol withdrawal in humans, is currently pending. The remaining authors declare no conflicts of interest.

\section{REFERENCES}

Albanese A, Minciacchi D (1983). Organization of the ascending projections from the ventral tegmental area: a multiple fluorescent retrograde tracer study in the rat. J Comp Neurol 216: 406-420.

Arora D, Haluk DM, Kourrich S, Pravetoni M, Fernandez-Alacid L, Nicolau JC et al (2010). Altered neurotransmission in the mesolimbic reward system of Girk mice. J Neurochem 114: 1487-1497.

Bailey CP, Manley SJ, Watson WP, Wonnacott S, Molleman A, Little HJ (1998). Chronic ethanol administration alters activity in ventral tegmental area neurons after cessation of withdrawal hyperexcitability. Brain Res 803: 144-152.

Brodie MS (2002). Increased ethanol excitation of dopaminergic neurons of the ventral tegmental area after chronic ethanol treatment. Alcohol Clin Exp Res 26: 1024-1030.

Brodie MS, McElvain MA, Bunney EB, Appel SB (1999a). Pharmacological reduction of small conductance calciumactivated potassium current (SK) potentiates the excitatory effect of ethanol on ventral tegmental area dopamine neurons. J Pharmacol Exp Ther 290: 325-333.

Brodie MS, Pesold C, Appel SB (1999b). Ethanol directly excites dopaminergic ventral tegmental area reward neurons. Alcohol Clin Exper Res 23: 1848-1852.

Brodie MS, Shefner SA, Dunwiddie TV (1990). Ethanol increases the firing rate of dopamine neurons of the rat ventral tegmental area in vitro. Brain Res 508: 65-69.

Crabbe JC, Johnson NA, Gray DK, Kosobud A, Young ER (1982). Biphasic effects of ethanol on open-field activity: sensitivity and tolerance in $\mathrm{C} 57 \mathrm{BL} / 6 \mathrm{~N}$ and $\mathrm{DBA} / 2 \mathrm{~N}$ mice. J Comp Physiol Psychol 96: 440-451.

Diana M, Gessa GL, Rossetti ZL (1992a). Lack of tolerance to ethanol-induced stimulation of mesolimbic dopamine system. Alcohol Alcohol 27: 329-333.

Diana M, Pistis M, Muntoni A, Rossetti ZL, Gessa G (1992b). Marked decrease of A10 dopamine neuronal firing during ethanol withdrawal syndrome in rats. Eur J Pharmacol 221: 403-404.

Enoch MA (2008). The role of GABA(A) receptors in the development of alcoholism. Pharmacol Biochem Behav 90: 95-104.

Enoch MA, Hodgkinson CA, Yuan Q, Albaugh B, Virkkunen M, Goldman D (2009). GABRG1 and GABRA2 as independent predictors for alcoholism in two populations. Neuropsychopharmacology 34: 1245-1254.

Gallegos RA, Lee RS, Criado JR, Henriksen SJ, Steffensen SC (1999). Adaptive responses of gamma-aminobutyric acid neurons in the ventral tegmental area to chronic ethanol. J Pharmacol Exp Ther 291: 1045-1053.

Gessa GL, Muntoni F, Collu M, Vargiu L, Mereu G (1985). Low doses of ethanol activate dopaminergic neurons in the ventral tegmental area. Brain Res 348: 201-203.

Grace AA, Bunney BS (1984). The control of firing pattern in nigral dopamine neurons: single spike firing. J Neurosci 4: 2866-2876.

Griffin WC III, Lopez MF, Yanke AB, Middaugh LD, Becker HC (2009). Repeated cycles of chronic intermittent ethanol exposure in mice increases voluntary ethanol drinking and ethanol concentrations in the nucleus accumbens. Psychopharmacology 201: 569-580.

Guan JS, Haggarty SJ, Giacometti E, Dannenberg JH, Joseph N, Gao J et al (2009). HDAC2 negatively regulates memory formation and synaptic plasticity. Nature 459: 55-60.

Kakihana R, Brown DR, McClearn GE, Tabershaw IR (1966). Brain sensitivity to alcohol in inbred mouse strains. Science 154: 1574-1575.

Kalda A, Heidmets LT, Shen HY, Zharkovsky A, Chen JF (2007). Histone deacetylase inhibitors modulates the induction and expression of amphetamine-induced behavioral sensitization partially through an associated learning of the environment in mice. Behav Brain Res 181: 76-84.

Kalsi G, Prescott CA, Kendler KS, Riley BP (2009). Unraveling the molecular mechanisms of alcohol dependence. Trends Genet 25: $49-55$.

Koob GF (2003). Alcoholism: allostasis and beyond. Alcohol Clin Exp Res 27: 232-243.

Kumar A, Choi KH, Renthal W, Tsankova NM, Theobald DE, Truong HT et al (2005). Chromatin remodeling is a key mechanism underlying cocaine-induced plasticity in striatum. Neuron 48: 303-314.

Kumar S, Fleming RL, Morrow AL (2004). Ethanol regulation of gamma-aminobutyric acid A receptors: genomic and nongenomic mechanisms. Pharmacol Ther 101: 211-226.

Kumar S, Kralic JE, O’Buckley TK, Grobin AC, Morrow AL (2003). Chronic ethanol consumption enhances internalization of alphal subunit-containing GABAA receptors in cerebral cortex. J Neurochem 86: 700-708.

Lacey MG, Mercuri NB, North RA (1988). On the potassium conductance increase activated by $\mathrm{GABA}_{\mathrm{B}}$ and dopamine $\mathrm{D}_{2}$ receptors in rat substantia nigra neurones. $J$ Physiol 401: 437-453.

Lacey MG, Mercuri NB, North RA (1989). Two cell types in rat substantia nigra zona compacta distinguished by membrane properties and the actions of dopamine and opioids. J Neurosci 9: $1233-1241$.

Levine AA, Guan Z, Barco A, Xu S, Kandel ER, Schwartz JH (2005). CREB-binding protein controls response to cocaine by acetylating histones at the fosB promoter in the mouse striatum. Proc Natl Acad Sci USA 102: 19186-19191.

Liang J, Suryanarayanan A, Abriam A, Snyder B, Olsen RW, Spigelman I (2007). Mechanisms of reversible GABAA receptor plasticity after ethanol intoxication. J Neurosci 27: 12367-12377.

Lopez MF, Becker HC (2005). Effect of pattern and number of chronic ethanol exposures on subsequent voluntary ethanol intake in C57BL/6J mice. Psychopharmacology 181: 688-696.

Luscher C, Ungless MA (2006). The mechanistic classification of addictive drugs. PLoS Med 3: e437. 
Matthews DB, Devaud LL, Fritschy JM, Sieghart W, Morrow AL (1998). Differential regulation of $\operatorname{GABA}(A)$ receptor gene expression by ethanol in the rat hippocampus versus cerebral cortex. J Neurochem 70: 1160-1166.

Moonat S, Sakharkar AJ, Zhang H, Tang L, Pandey SC (2013). Aberrant HDAC2-mediated histone modifications and synaptic plastcity in the amygdala predisposes to anxiety and alcoholism. Biol Psychiatry 3223: 00052-00058.

Moonat S, Starkman BG, Sakharkar A, Pandey SC (2010). Neuroscience of alcoholism: molecular and cellular mechanisms. Cell Mol Life Sci 67: 73-88.

Mueller AL, Brodie MS (1989). Intracellular recording from putative dopamine-containing neurons in the ventral tegmental area of Tsai in a brain slice preparation. J Neurosci Methods 28: $15-22$.

Oades RD, Halliday GM (1987). Ventral tegmental (A10) system: neurobiology. 1. Anatomy and connectivity. Brain Res 434: 117-165.

Pandey SC, Ugale R, Zhang H, Tang L, Prakash A (2008). Brain chromatin remodeling: a novel mechanism of alcoholism. J Neurosci 28: 3729-3737.

Papadeas S, Grobin AC, Morrow AL (2001). Chronic ethanol consumption differentially alters GABA(A) receptor alpha1 and alpha4 subunit peptide expression and $\operatorname{GABA}(\mathrm{A})$ receptormediated $36 \mathrm{Cl}(-)$ uptake in mesocorticolimbic regions of rat brain. Alcohol Clin Exp Res 25: 1270-1275.

Parker JG, Wanat MJ, Soden ME, Ahmad K, Zweifel LS, Bamford NS et al (2011). Attenuating GABAA receptor signaling in dopamine neurons selectively enhances reward learning and alters risk preference in mice. J Neurosci 31: 17103-17112.

Renthal W, Maze I, Krishnan V, Covington HE III, Xiao G, Kumar A et al (2007). Histone deacetylase 5 epigenetically controls behavioral adaptations to chronic emotional stimuli. Neuron 56: 517-529.
Renthal W, Nestler EJ (2008). Epigenetic mechanisms in drug addiction. Trends Mol Med 14: 341-350.

Renthal W, Nestler EJ (2009a). Chromatin regulation in drug addiction and depression. Dialogues Clin Neurosci 11: 257-268.

Renthal W, Nestler EJ (2009b). Histone acetylation in drug addiction. Semin Cell Dev Biol 20: 387-394.

Sakharkar AJ, Zhang H, Tang L, Shi G, Pandey SC (2012). Histone deacetylases (HDAC)-induced histone modifications in the amygdala: a role in rapid tolerance to the anxiolytic effects of ethanol. Alcohol Clin Exp Res 36: 61-71.

Shen R-Y, Chiodo LA (1993). Acute withdrawal after repeated ethanol treatment reduces the number of spontaneously active dopaminergic neurons in the ventral tegmental area. Brain Res 622: 289-293.

Shibasaki M, Mizuno K, Kurokawa K, Ohkuma S (2011). Enhancement of histone acetylation in midbrain of mice with ethanol physical dependence and its withdrawal. Synapse 65: $1244-1250$

Starkman BG, Sakharkar AJ, Pandey SC (2012). Epigeneticsbeyond the genome in alcoholism. Alcohol Res 34: 293-305.

Stobbs SH, Ohran AJ, Lassen MB, Allison DW, Brown JE, Steffensen SC (2004). Ethanol suppression of ventral tegmental area GABA neuron electrical transmission involves N-methyl-Daspartate receptors. J Pharmacol Exp Ther 311: 282-289.

Sweatt JD (2009). Experience-dependent epigenetic modifications in the central nervous system. Biol Psychiatry 65: 191-197.

Whittemore ER, Yang W, Drewe JA, Woodward RM (1996). Pharmacology of the human gamma-aminobutyric acidA receptor alpha 4 subunit expressed in Xenopus laevis oocytes. Mol Pharmacol 50: 1364-1375.

Xiao C, Ye JH (2008). Ethanol dually modulates GABAergic synaptic transmission onto dopaminergic neurons in ventral tegmental area: role of mu-opioid receptors. Neuroscience 153: $240-248$. 